\title{
RELATION OF GENETICS TO POPULATION STUDIES
}

A

WELL-ATTENDED joint session of Sections D, $I$ and $J$ (Zoology, Physiology and Psychology) of the British Association took place in Bristol on September 2, the general topic being "Genetics and Medicine".

In the opening paper, Dr. H. Grüneberg (University College, London) discussed the use of "Inherited Diseases in Animals as a Tool in Medical Research". The laboratory rodents have provided a large number of inherited conditions, including many with close counterparts in man. Many of these are caused by single genes; but equally important are inherited diseases conditioned by an array of genes which occur in a high frequency in some inbred strains, but are rare or absent in others. The use of this material opens up certain important fields of research which are inaccessible in man himself. The majority of inherited diseases and anomalies due to single genes arise in early development, and as early human embryos with the initial phases of such anomalies are scarcely ever available for study, a step-by-step investigation of abnormal development is entirely dependent on animal material.

Direct observation shows that the mechanisms underlying abnormal development are often quite different from those of classical pathology. For example, a reduction of the vertebral bodies with absence of the odontoid process of the axis in a mouse mutant is due to an early degeneration of the notochord. Widespread skeletal anomalies associated with the gene for congenital hydrocephalus in the same animal are due to general reduction in size of the mesenchymal skeleton as it is formed, and threshold mechanisms determine the absence of some elements, fusions between others, etc. In a third instance, anomalies of the vertebral column, again in the mouse, are traceable to a faulty distribution of mesenchymal material, too much being used for the intervertebral disks and too little for the vertebræ themselves.

The pathology of development is thus a new field entirely dependent on animal material. The discovery of several inherited types of deafness in the mouse is likely to assist in the understanding of the pathology of human deafness, which is greatly hampered by technical difficulties not encountered in animal material. Important progress has been made by the use of resistant and susceptible strains of animals in analysing the physiological basis for disease resistance. The use of animal material for studying diseases of old age, so familiar in cancer research, was illustrated by amyloid degeneration and cystic kidney disease in a certain strain of mice and its absence in others; what could scarcely have been discovered in man is the fact that this inherited tendency to amyloidosis can be almost completely suppressed on certain low-protein diets.

In a paper on the "Causation in Mental Deficien. cies", Dr. J. A. Fraser Roberts (London School of Hygiene and Tropical Medicine) pointed out that gene differences in certain rare types of mental deficiency have provided important general information ; for example, the first estimate of an autosomal mutation-rate in vertebrates was made with tuberose sclerosis (epiloia). There is evidence that some modest proportion of severe mental deficiency, in addition to a few rare special types, is determined by recessive genes. The great bulk of mental deficiency, however, is a heterogeneous collection the causation of which presents difficult problems. The most useful division of the mental deficiencies is into two groups which may be ascribed to major errors of development, whether genetic or non-genetic. Mild defect shows the signs of some measure of multifactorial determination, together with multiple environmental influences. In spite of the difficulties of measurement, the evidence seems to point to little real underlying overlapping. The incidence of severe defect among the brothers and sisters of those mildly affected is little if at all greater than in the general population. Conversely, apart from the sibs also severely affected, the intelligence of the sibs of those severely affected is little lower on the average than in the general population. Much, or possibly all, the apparent lowering is an artefact due to the methods of sampling. A substantial part of the resemblance between relatives in level of intelligence (including mild mental deficiency) is probably environmental.

Penrose's studies and Dr. Fraser Roberts's own yield a correlation between first cousins which is double what it should be, given the correlation between sibs. It seems reasonable to conclude that while the genes in common are reduced to one-quarter in cousins as against sibs, environmental similarities fall off much more slowly as relationship becomes more remote. It is possible that some major nongenetic causes affecting intelligence adversely may be identified. For example, there is the definite lowering in twins, as found in the Scottish survey. There is also the evidence that prematurity is much commoner among high-grade and borderline defectives than in the general population.

Dr. E. T. O. Slater (Genetic Unit, Institute of Psychiatry, University of London) gave a brief general report on "Work on Twins in Psychological Medicine", in which he reviewed particularly twin studies on the causes of schizophrenia and of crim. inality; in the latter, earlier studies had suggested a predominant influence of heredity; but in more recent work, factors like early background and family tradition, special opportunities and temptations have now emerged as significant causes. In Dr. Slater's own work (jointly with Mr. James Shields) on the causes of 'neurosis', the comparison between monozygotic and dizygotic twin pairs has produced evidence that the tendency to neurosis is, at least in part, under genetic control.

The main emphasis of the work was, however, on the environmental causes of the breakdown. These were studied through the differences which were found between the partners of monozygotic twin pairs, the differences being caused by the inter-twin relationship (one twin tending to take on more of the leadership, etc.), the relationship with parents, the marital relationship, by differences in occupational stress and of physical health, and finally by differences in psychological stress other than those covered above. In nearly all cases, causes are multiple, though very often a single factor can be picked out as the most important. Generally, Dr. Slater considers that the causes of neurotic illness are intelligible at a commonsense level and do not seem to require recondite hypotheses. Among causes operating from early in child life, those which persist for years (for ex- 
ample, the type of training) seem to be the most important.

Prof. L. S. Penrose (Galton Laboratory, University College, London) demonstrated in his paper on "Mutation and Parental Age" that human material may in certain cases yield results superior to those usually obtained from experimental animals. The spontaneous mutation-rates of a number of ('dominant') human genes have been estimated by direct observation of freshly arising cases, that is, of ab. normal children born of normal parents. In other cases, an indirect method has been used which is based on the supposition that elimination by selection of a gene with deleterious effects must be balanced by newly arising mutations, the overall frequency of the condition remaining approximately constant.

Additional information about possible causes of mutations has now been obtained from a consideration of parental age. For example, if a certain gene is particularly sensitive to ionizing radiation to which parents are exposed throughout their lives, mutations at that locus will be proportional to parental age such that the trait will be twice as common among offspring of parents aged forty as among those with parents aged twenty years. Looked at in another way, the parents of children carrying newly mutated genes will be older than the average parent. Some evidence (unfortunately from maternal ages only) of an increase of mutation-rate with age comes from microphthalmia, and there is less complete evidence of an effect of both paternal and maternal age in the case of epiloia and retinoblastoma. The incidence of achondroplasia (born of normal parents and hence presumably due to a new mutation) depends strikingly on the age of the father, but there seems to be little or no effect of the age of the mother ; in the latter case, a possible interpretation is that, while the epiloia locus is sensitive to natural radiation, the achondroplasia locus is sensitive to agencies specially active at some stage in cell division, perhaps chemical mutagens. The relative absence of cell division in the female germ track, as compared with the male germ track, would explain the lack of independent maternal effects. The dependence or otherwise of mutation-rate on parental age thus affords some information on possible causes of 'spontaneous' mutations not so far obtainable from data on spontaneous mutations in animals.

The concluding paper, by Dr. C. O. Carter (secretary, Eugenics Society), dealt with "Genetics and Child Health". In recent years, deaths from diseases of childhood due to environmental causes (mainly infections) have declined sharply. As a result, the groups of diseases mainly or partly due to genetical causes loom much larger. An indication of the changes in relative importance is given by the cause of death in two hundred consecutive children undergoing post. mortem investigation in a children's hospital in each of the years 1914 and 1954. The group of diseases caused by environment was more than two-thirds of the whole in 1914, but less than one-seventh in 1954; the group of diseases mainly genetical in origin was only one-fiftieth of the whole in 1914 but one-eighth in 1954; diseases of mixed causation were less than one-seventh of the whole in 1914, but more than a quarter in 1954, while diseases of unknown eausation rose from less than a quarter in 1914 to nearly a half in 1954 .

Looking to the future, Dr. Carter believes that, while the environmentally caused group of diseases will continue to fall, the diseases of mixed origin will probably be only slightly reduced by environmental measures. Reduction in the proportion of children born with genes predisposing to these disorders can only be achieved by reducing the average number of generations through which disadvantageous gene mutations can persist in the population. At the moment, such mutations are tending to last longer as new methods of treatment keep those affected alive to an age at which they can bear children. Probably the most ethically correct way of bringing about a reduction in the average number of generations a mutation persists is to enlist the co-operation of parents who are unlucky enough to carry major disadvantageous mutations, in planning to keep the number of their children below replacement-rate.

\section{OBITUARIES}

\author{
Prof. J. C. Flugel
}

Prof. John Carl Fluger died suddenly at his home in London on August 6. He was one of the few survivors of the small band of British psychologists who received their training at Oxford under William McDougall. McDougall's views on the nature of mind and the way psychological questions should be approached influenced nearly all that Flugel wrote ; yet he himself succeeded in developing a wholly original attitude.

His earliest researches were carried out in the laboratory at Oxford, and dealt with such practical problems as intelligence testing, visual adaptation at night, the measurement of mental fatigue and the causes of the oscillations of attention. After his appointment as lecturer at University College, London, he remained for many years in charge of the experimental work in the Department of Psychology. His chief interest, however, lay in the deeper problems such as in those days were relegated to the somewhat dubious regions of psychoanalytic study and psychical research. He was the first professional psychologist to make a serious examination of Freud's early theories. These he endeavoured to re-interpret in terms of current British psychology. Thus, while the medical profession still looked askance at the novel and extravagant doctrines of the Freudian School, he did much to popularize their chief conclusions by recasting them in a more acceptable form. The outcome was a series of papers on psycho-analytical topics which appeared in various scientific journals, and were later collected and re-issued in book form.

Of his larger works, the first was "The Psychoanalytic Study of the Family" (1921), which attracted immediate attention. The most popular was probably his "Psychology of Clothes" (1930). "A Hundred Years of Psychology" (1933) presents an admirable historical review of the development of psychology from 1833 to the date of publication, and is still read as a regular text-book. The lucid style, the flashes of humour, the widespread sympathy and tolerance which distinguish all his writings were also a marked feature of his personal teaching, and endeared him to numerous students who came to his classes from all over the world.

In 1929 Flugel was made assistant professor, and retained this post until his retirement in 1944. A good deal of his time was spent in practical psychoanalytical work with patients and normal persons; and the results led to many valuable contributions to psychological and psychiatric theory. The more 